\title{
Análisis e interpretación iconográfica de las representaciones antropomorfas de la cultura Jama Coaque
}

Andrés Gutiérrez Usillos ${ }^{1}$

\begin{abstract}
RESUMEN
A partir del estudio iconográfico de representaciones antropomorfas de la cultura Jama-Coaque,

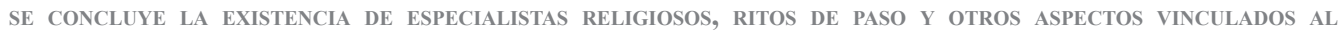
PENSAMIENTO SIMbÓlico de ESTA CULTURA. EN ESTE ARTíCULO SE ABORDA ADEMÁS UN ESQUEMA DE APROXIMACIÓN A LA DESCRIPCIÓN DETALLADA DE ESTAS FIGURAS ANTROPOMORFAS DE CARA A LA COMPARACIÓN DE DATOS Y ELABORACIÓN DE PROPUESTAS INTERPRETATIVAS.
\end{abstract}

Palabras clave: Jama Coaque - iconografía - Religiosidad - figuras antropomorfas - Simbolismo.

\section{Abstract}

USING AN ICONOGRAPHIC STUDY BASED ON THE ANTHROPOMORPHOUS REPRESENTATIONS OF THE JAMA-COAQUE CULTURE, THE EXISTENCE OF RELIGIOUS SPECIALISTS, RITES OF PASSAGE AND OTHER ASPECTS LINKED WITH THE SYMBOLIC WAY OF THINKING OF THIS CULTURE ARE PROVEN. THIS ARTICLE ALSO MENTIONS A SCHEME OF APPROXIMATION OF THE DETAILED DESCRIPTION OF THESE ANTHROPOMORPHOUS FIGURES IN CONTRAST WITH THE DATA AND THE ELABORATION OF THE INTERPRETIVE PROPOSITIONS.

KeY WORDS: JAMA-COAQUE - ICONOGRAPHY - RELIGIOUSNESS - ANTHROPOMORPHOUS FIGURES - SYMBOLISM.

1 Conservador Jefe del Departamento de América Precolombina. Museo de América.

Este artículo forma parte del proyecto de investigación del Programa Prometeo, 2013-2014, financiado por el Gobierno Ecuatoriano a través de SENESCYT (Acta CEB-PROMETEO 005-2013) titulado Propuesta de sistema documental integrado para colecciones de arqueología ecuatoriana y ejemplificación en la cultura Jama-Coaque del museo MAAC. Guayaquil, 2014. 


\section{Introducción}

$\mathrm{E}$ 1 acercamiento al pasado y el conocimiento de las antiguas culturas puede abordarse de múltiples perspectivas y enfoques, ya sea desde la Historia a través de los documentos escritos, desde la Arqueología mediante la excavación minuciosa de las evidencias materiales en sus contextos, incluso desde la Lingüística o la Genética a través de relaciones o raíces comunes de vocablos o de rasgos genéticos, y por supuesto a través de la combinación de varios de ellos.

Uno de los métodos más factibles para algunas culturas y que ofrece resultados de gran interés es el del análisis iconográfico². Y la cultura Jama Coaque del Ecuador prehispánico es un ejemplo evidente de lo que, a través del estudio de las ricas y variadas representaciones en cerámica puede llegar a conocerse e interpretarse sobre una cultura de la que no quedan apenas testimonios escritos -y los que se conservan tienen la visión sesgada y subjetiva de los conquistadores europeos-, y que tampoco cuenta con suficientes estudios arqueológicos que permitan responder a algunas preguntas básicas. Por ejemplo ¿cómo era el pensamiento religioso o cual era su principal manifestación ritual?

De este modo, no resulta sencillo acceder a la interpretación del mundo simbólico y religioso sin recurrir a las analogías etnográficas o históricas. Sólo estas vías paralelas posibilitan ciertas aproximaciones sobre el sistema de pensamiento en el pasado y su plasmación material en los objetos recuperados, que hoy custodian los museos, aunque la mayoría carecen de otros contextos.

\section{La cultura Jama Coaque: rasgos para su definición}

A poco que uno comienza a investigar sobre esta cultura, que cuenta con una riqueza material extraordinaria, realmente asombra la escasa información que existe con relación al "modo de vida" de los hombres y mujeres que produjeron y utilizaron estos objetos cerámicos. Sorprende más aún teniendo en cuenta que Pizarro y sus huestes ocuparon varios meses el poblado de Coaque, aguardando los refuerzos que desde Panamá tenían que llegar para poder iniciar la conquista del territorio Inca. Meses que, salvo algunos documentos referidos al reparto del botín de Coaque (Hampe Martínez, 1989), pasan casi totalmente desapercibidos y no han dejado descripciones o testimonios sobre la forma de vida en el poblado indígena.

Afortunadamente, la cultura Jama Coaque ha "legado" a la posteridad un abundante y preciso retrato cerámico de su cotidianidad. En estas vasijas y figuritas podemos reconocer a los protagonistas, es decir, hombres y mujeres, caciques, chamanes o sacerdotes y sacerdotisas, en diferentes actitudes. Los artistas y artesanos reflejan en sus imágenes, un mundo real o simbólico propio, el que pertenece a su cultura, y por lo tanto, a partir de estas imágenes es posible remedar ciertos aspectos de la misma. Aunque siempre debemos tener en consideración la carga subjetiva del investigador en el análisis que se realiza.

La principal dificultad para interpretar el conjunto de cerámicas Jama Coaque tiene relación con la amplitud cronológica que abarca. Esta cultura se extiende por los dos períodos cronológicos (Desarrollo Regional e Integración) con una duración de casi dos mil años -desde el 350 a.C. a 1532 d.C.-. Aún no se ha realizado una secuenciación tipológica de las figuras antropomorfas 3 , a la que habría que añadir las variantes regionales que se aprecian en la diferenciación estilística de estas figuras.

Podemos afirmar que se trata de una o varias jefatura/s compleja/s organizadas en torno a una serie de asentamientos ceremoniales jerarquizados, los cuales parecen agruparse en cuatro

2 Para ampliar el concepto consultar la publicación de María Fernanda Ugalde (2009) donde se describe con precisión el método de trabajo con la perspectiva iconográfica en el análisis de la cultura Tolita.

3 Si bien, en relación con la cerámica, Zeidler ha clasificado en 4 fases denominadas Muchique I a IV (Zeidler, J. y Stuliff, 1994). 
tamaños y funciones diferenciadas ${ }^{4}$. Los de mayor tamaño, con una gran tola o pirámide central como el sitio de San Isidro (Zeidler, 1994), controlan las actividades económicas, sociales y sobre todo religiosas, mientras que otros espacios de carácter secundario, así como asentamientos dependientes, dispersos pero relacionados entre sí, parecen desarrollar más bien actividades productivas.

Estos centros ceremoniales deben ponerse en relación con las representaciones antropomorfas de sacerdotes y de caciques sobre taburetes, claramente diferentes de las de chamanes o de las de guerreros y otros grupos masculinos Jama Coaque. Parece evidente que los sacerdotes, si bien no ejercían el poder político, articulaban todo el entramado social y su funcionamiento. ¿Quiénes eran entonces los sacerdotes? ¿Se trataba de hombres, de mujeres, o de ambos? ¿Pertenecían exclusivamente a las élites dominantes o eran elegidos por algún tipo de designio sobrenatural? ¿Cuáles eran sus rasgos o atributos principales? ¿Qué papel jugaba el conocimiento del medio natural para la predicción del clima o la planificación del calendario? ¿De qué forma se realizaban los rituales? En resumen ¿quién dirigía el calendario ritual y qué tipo de ceremonias practicaban?

En este estudio no sólo nos planteamos dar una explicación a estas cuestiones a partir de hipótesis de interpretación de los rasgos representados en las figuritas antropomorfas, sino que también abordamos una consideración de carácter práctico. ¿Cómo podemos gestionar la información catalográfica de estos objetos cerámicos de forma que se posibilite un análisis comparativo?

A la hora de abordar un estudio iconográfico es necesario poder comparar múltiples datos y variables y por lo tanto tener una tabla o base de datos que aglutine toda esta información clasificada. De esta forma, por ejemplo, podríamos dar respuesta a otras preguntas sobre el conjunto analizado, como ¿cuántas de las figuritas representan personajes femeninos, o cuáles de ellas están sentadas sobre taburetes, y cuáles de éstas sostienen en sus manos objetos vinculados con el consumo de coca? Lo que nos permitiría inferir la existencia de mujeres en roles de poder y actitudes preferentemente masculinas. Realmente, lo que resultaría de mayor interés es que la tabla que se desarrolle nos permita realizar múltiples combinaciones para dar con el dato que se precise 5 .

\section{Rasgos que permiten realizar agrupaciones en las figuras antropomorfas}

No pretendemos repetir aquí los rasgos estilísticos de las representaciones antropomorfas Jama Coaque, teniendo en cuenta además que existen suficientes variantes como para que fuera necesario realizar un buen número de precisiones que quedan fuera de nuestro objetivo. Algunos rasgos generales que se repiten en las representaciones antropomorfas son, por ejemplo, la realización de los ojos con la forma de " $\mathrm{D}$ " caída, con el lado recto en horizontal, o la aplicación profusa del color, sobre todo el azul-verdoso, característico de esta cultura y especialmente un gran barroquismo en las composiciones con muchos detalles y aplicaciones.

Para el análisis iconográfico de figuras antropomorfas por tanto, es necesario establecer asociaciones o la reiteración de rasgos que se repiten en las figuras y que nos dan pautas de conducta o indicios para la interpretación. Y para ello podrá ser de gran utilidad la realización de una tabla descriptiva en la que se recojan los campos específicos que puedan ordenarse y agruparse de manera conveniente. De hecho, a través del Proyecto Prometeo, en el Museo de Antropología y Arte Contemporáneo de Guayaquil (MAAC), y con la coordinación de Mariella

4 Según Oswaldo Tobar (1988: 313 y ss.) estos cuatro tipos de asentamiento serían: el Centro Regional que equivale al centro religioso y administrativo, con más de 30 ha., la Aldea Aglutinada entre 7 y 30 ha., los Caseríos de 1 a 7 ha. que albergarían dos o tres familias extendidas, y las Estancias con menos de 1 ha.

5 En el proyecto desarrollado en el MAAC se parte de una propuesta de datos en una tabla excel, que se espera, con el apoyo del área informática de este museo, poder trasladar a una base de datos para consulta. Estamos también trabajando para que esa tabla sirva igualmente para la catalogación de otros objetos, aunque tenga especial incidencia en el aspecto iconográfico. 
García Caputi y apoyo del personal técnico de la institución, hemos venido desarrollando esta tabla de descripción iconográfica e información de objetos cerámicos que permite cruzar datos y variables. Básicamente, hemos procurado agrupar los campos necesarios para la descripción exhaustiva en cuatro bloques principales de información, a los que habría que sumar algunos otros datos de interés, como la función del objeto, características técnicas y constructivas, tipo de pasta, engobe, pintura, decoración, etc.

- Los rasgos referentes a las características físicas del individuo representado deben individualizarse en subcampos específicos que nos permitan combinarlos con otras variables, tal y como señalamos, por ejemplo la utilización del taburete o el consumo de llipta. El sexo, la edad, si es zurdo o diestro -en función de la mano con la que maneja el objeto principal-, y otras características físicas del personaje como la corpulencia, el tamaño de los miembros, o discapacidades, enfermedades, etc., son los datos a recoger en campos diferenciados. Con estos datos se pueden ir realizando estadísticas ${ }^{6}$, en las que se aprecia por ejemplo, una preponderancia de figuras masculinas, $57 \%$ frente a $40 \%$ femeninas, y que nos van a mostrar también el papel que cada sexo cumple en la sociedad. El sexo de la figura la mayor parte de las veces no es evidente, ya que suele estar cubierto o bien con taparrabos en el caso masculino o con faldellín en el femenino, lo que permite interpretar en su caso el "sexo social" que la figura representa. En ocasiones, además, el artista ha querido reflejar una dualidad o una ambigüedad sexual, mostrando rasgos de un género con indumentaria de otro, lo que resulta también de gran interés para describir los grupos socio-sexuales.

- Atributos simbólicos de los personajes que también es preferible tratar de forma individualizada, como marcas, tatuajes, colores de pintura facial o corporal, posición del cuerpo, forma de sentarse, posición de las manos o los dedos que, en relación con las otras categorías, permiten establecer grupos concretos de personajes y acciones dentro de los anteriores.

- La Indumentaria y los adornos también se desglosan en campos específicos: tocado o adornos de cabeza, poncho/camiseta, faldellín, etc. La indumentaria resulta de gran utilidad no sólo para identificar el sexo o más bien el género social del individuo como hemos mencionado, sino obviamente la función que desempeña dentro del conjunto de la sociedad, evidente en el caso del chamán. E igualmente es útil para definir el estado o situación del individuo que se pretende reflejar, por ejemplo, a través de un tocado especial para los ritos de paso femeninos o vestimentas de danzantes, etc. Como parte de la indumentaria podemos incorporar también las referencias y descripciones de adornos faciales (piercing, orejeras, bezotes, clavos...), collares, pulseras, pectorales, cinturones, senojiles y tobilleras.

- Ajuares, u otros elementos que acompañan a la figura, sobre todo aquellos que sostiene con las manos, y que permiten su reconocimiento o identificación en relación a una actividad específica o profesión, en muchas ocasiones complementaria de la indumentaria. Por ejemplo, las armas -estólicas, lanzas y escudos-, en el caso de los guerreros, instrumentos musicales, o útiles para el consumo de alucinógenos como la llipta y la espátula o palillos, etc. Es importante nuevamente reflejar el tipo de objetos uno a uno, individualizados, señalando la mano con la que los sostiene, porque esto nos permite identificar la representación de personajes zurdos, que como hemos indicado en otras publicaciones, en el caso de los sacerdotes es un porcentaje significativamente reseñable (Gutiérrez, 2011).

6 El dato, aunque extrapolable estadísticamente, obviamente está sesgado por un doble filtro inicial, por un lado de los materiales que se han conservado y por otro, de aquellos a los que he tenido acceso o conocimiento. 


\section{Chamanes y sacerdotes en la Cultura Jama Coaque}

Para definir la presencia de varios conjuntos de chamanes, nos detendremos a analizar el tipo de indumentaria o de vestimenta específica, además de cierta pintura corporal y sobre todo una parafernalia apropiada a su cargo. Pensamos además que se trata de chamanes individualizados, personajes concretos que se representan con diferentes adornos en función del rango y estatus que ocuparon en vida y que eran por ello reconocibles por el resto del conjunto de la sociedad.

Uno de los principales grupos dentro de la iconografía antropomorfa Jama Coaque es el que conforman los chamanes masculinos con poncho y tocado adornado con caracoles. En este grupo observamos algunos de los pocos ejemplos que muestran a estos chamanes sentados en estos bancos, y además parecen repetir los rasgos iconográficos del atuendo casi invariablemente (figura 1), lo que sugiere que se trata de individuos que además de tener el cargo de chamán contaron con el privilegio de rango de los caciques para la utilización del banco.

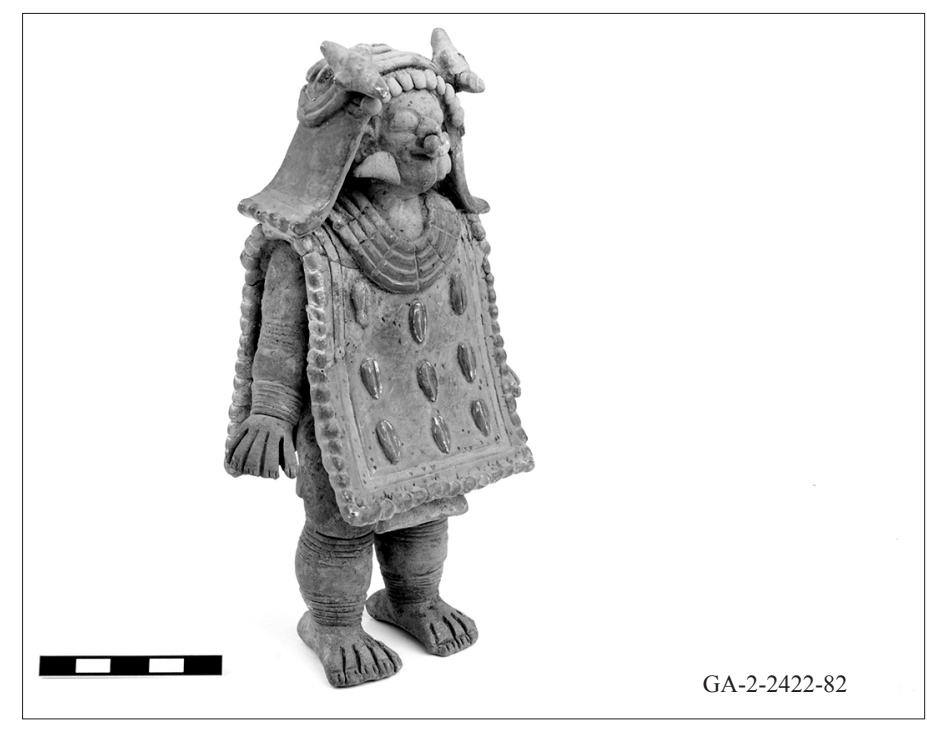

Figura 1. Chamán masculino Con poncho y tocado

Aunque el comentario estaba referido a Bahía de Caráquez, al sur del territorio ocupado por la cultura Jama Coaque, Agustín de Zárate (1947), menciona que a la entrada de los templos se distinguía la presencia de figuras o representaciones de "hombres vestidos con dalmáticas". El cronista entendía o conocía que se trataba de retratos de personajes masculinos y en su asociación con la dalmática, una especie de poncho largo o túnica abierta a los lados pretende, consciente o inconscientemente, relacionar a estos personajes con los diáconos o sacerdotes de los templos cristianos. Así que este tipo de indumentaria parece vincularse a los chamanes o sacerdotes y específicamente los que se adornan con ciertos elementos, como los caracoles.

Las caracolas que adornan los tocados (figura 2) varían en forma y longitud, aunque en general parecen responder a la forma de las Fasciolarias, y dentro de éstas quizá pudieran estar representando ejemplares de Fusinus o Knefastia. El hábitat de algunas especies de Fusinus es similar al del Spóndylus, por lo que probablemente también cumplieron un papel destacado en la predicción climática o como indicador estacional en la cultura Jama Coaque, más evidente o significativo que el del propio Spóndylus. 
Al contabilizar el número de los caracoles en el tocado, observamos una relación con el tipo de indumentaria y la complejidad de los adornos del chamán. Esto sugiere la existencia de una aparente vinculación entre el número y tamaño de los caracoles en el tocado y el rango o nivel de destreza del chamán, lo que evidencia una jerarquía dentro de este grupo vinculada a la potencia, experiencia o capacidad del chamán en relación con su función.

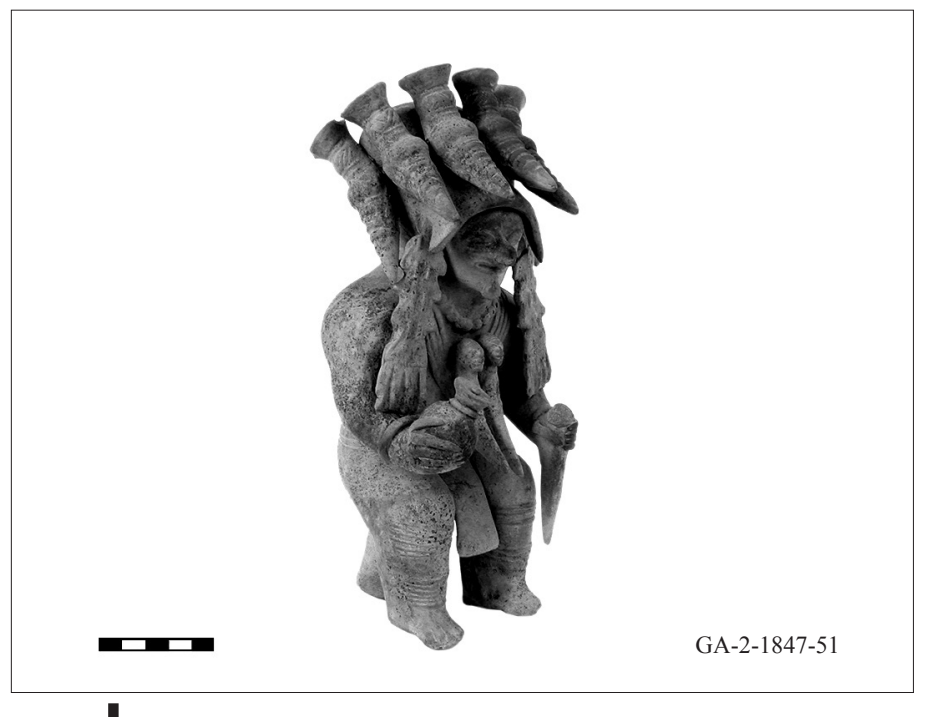

Figura 2, Chamán masculino adornado Con Caracoles

El resto de caracolillos que forman parte de la indumentaria chamánica se representan cosidos al tocado y al poncho ${ }^{7}$, son ya de menor tamaño, forma ovalada o elíptica y muestran el canal de apertura central continua, en toda su longitud. A través de estas representaciones también es difícil identificar la especie concreta, si bien en contextos arqueológicos se han recuperado ejemplares trabajados del género Oliva sp., lo que permite suponer que se trataría de esta misma especie. Su función, además de la evidente relación simbólica con el agua, sería la de producir sonido de cascabeles.

Al realizar estas agrupaciones de personajes ataviados con poncho y tocado de caracoles, observamos un grupo concreto, que se caracteriza por la anatomía física del personaje y por la ausencia general de caracolas en el tocado (figura 3). Uno de los rasgos que los identifican, además de la anatomía acondroplásica o el acortamiento de extremidades y cuello, es la presencia de largas uñas en los pulgares, que hemos relacionado con los auxiliares de chamanes que realizaban sacrificios de pequeños animales (Gutiérrez Usillos, 2011), como describe a finales del siglo XVI Bartolomé Álvarez para distintas ceremonias de la región central andina: "Mátalo, o retorciéndolo la cabeza o rompiéndole el gaznate con una uña muy sucia y larga del dedo pulgar, y la sangre derramándola en la tierra." (Álvarez, 1998 [1588]: 85)

Más explícito sobre esta forma de sacrificio de animales utilizando la uña y sobre todo la posterior lectura de entrañas es la que describe esta otra crónica anónima:

"A los cuyes les clavaban la uña del pulgar derecho por el pescueço por junto a la uia del tragadero y luego le torcían la cabeça a un lado, de suerte que por la herida salia la sangre en hilo delgado y con

7 En una figura Jama Coaque masculina con poncho (MAAC GA-21.962.78) se aprecian las pequeñas conchas o caracolillos cosidos al mismo. 
ella puesta en frente del ídolo lo rociauan.... Al cuy con las mismas uñas de los pulgares que para este propósito trayan muy largas. Los abrian y les sacauan los bofes y los soplaban por el caño del tragadero y como los bofes son esponjosos se hinchaban llenandose de uiento y si quedaban lisos sin ninguna grieta ni quebradura era buena señal y dauan la respuesta aduersa.” (Anónimo [1603]: Crónica de Chinchaycocha)

Se confirma también para esta cultura Jama Coaque la existencia de una jerarquía de sacerdotes, pues la presencia de este grupo de auxiliares para los sacrificios, señala claramente la existencia de especialistas religiosos con una categorización inferior a la del sacerdote principal que tiene su reflejo en la propia indumentaria del individuo.

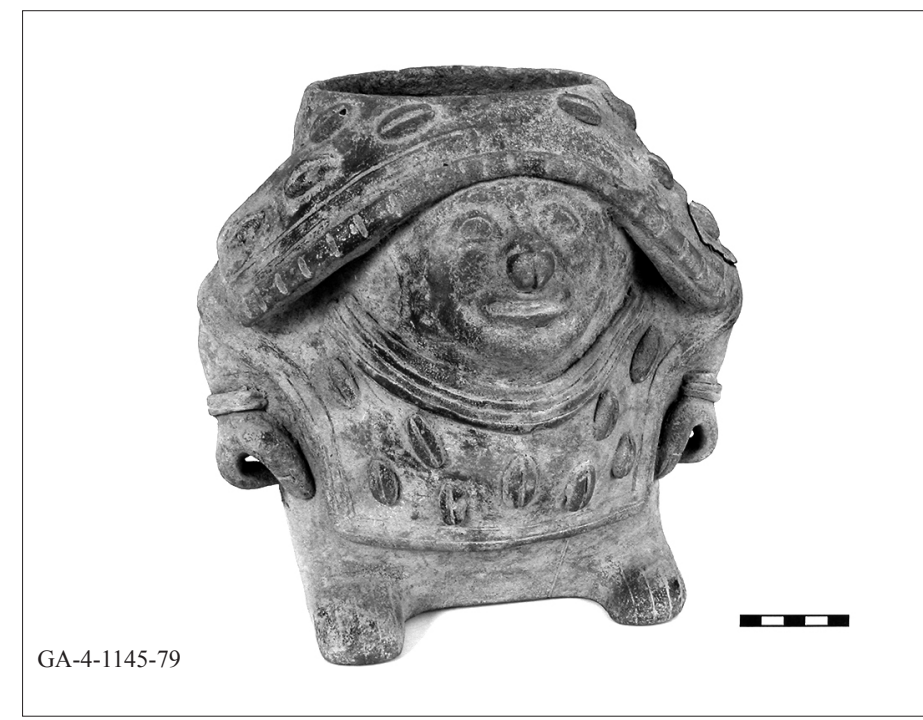

Figura 3. Chamán masculino sin Caracolas en tocado

\section{Chamanes con tocados de aves}

En la agrupación iconográfica de personajes según los rasgos ya mencionados, advertimos dentro del grupo masculino la preponderancia de otro grupo de chamanes con adornos faciales diferenciados del resto de la población -específicamente el bezote trapezoidal, que hemos reconocido como uno de los rasgos de estos sacerdotes/chamanes-, que muestra aves en el tocado, en lugar de las referidas caracolas. Entre los rasgos generales se observa la ausencia del poncho, y parecen mostrar mayor profusión de adornos faciales y una evidente asociación con ciertos frutos como la piña. Además, en lugar de elementos de concha utilizan adornos de oro -orejeras, bezotes y sobre todo los tincullpa o pectorales que representan el disco solar-.

Finalmente, estos chamanes son además músicos pues se muestran tocando la antara o flauta en $\mathrm{W}$, relacionándose no tanto con el sacrificio de sangre, como en el caso anterior, sino con la música, el buen tiempo, las aves y los frutos.

Sorprendentemente existe una contradicción o una "desconexión" entre las representaciones iconográficas más frecuentes y los restos arqueobotánicos recuperados. Las representaciones muestran una relación preferente de los chamanes con los tubérculos, o algunos frutos como la 
piña, e incluso leguminosas como el maní, plantas que si bien no parecen haber dejado la misma huella en el registro arqueológico ${ }^{8}$ que el mencionado cereal, debían tener una importancia simbólica mayor. Los restos botánicos recuperados en las excavaciones arqueológicas indican que el maíz, fréjol y calabaza eran cultivos prioritarios y sin embargo, la yuca parece estar constantemente ausente o la piña ser un alimento secundario. Esto podría explicarse, en parte, por la dificultad de conservación tanto de pólenes como de fitolitos de yuca, como señalaba Diógenes Patiño (2006) para Tumaco-Tolita.

En todo caso, observamos cómo en Jama Coaque la distribución de sacerdotes especializados se distribuye en relación con el ciclo agrícola anual. El sacerdote o chamán que predice y controla la climatología es un personaje frecuente en diferentes culturas, es el conjurador de nubes que interfiere mágicamente sobre los elementos atmosféricos. También es conocido como tempestero, granicero, nubeiro, ventero, o tempesterii y se reconoce como profesión desde la Edad Antigua en casi todo el mundo. En el ámbito prehispánico, estos chamanes Jama Coaque tendrían su contrapartida también en Perú, en la figura del Altamisayoq o su equivalente mexicano de los conjuradores de nublados ${ }^{9}$.

Es evidente que una cultura como la de Jama Coaque cuya base económica se asienta en la producción agrícola, necesita tener un control sobre las estaciones y lluvias que permitan regular los ciclos de siembra y recolección. Por tanto, los atuendos y parafernalia de estos personajes masculinos descritos sugieren la articulación del complejo ceremonial de esta cultura en torno a dos conjuntos principales de ceremonias, el de siembra y el de recolección, con dos tipos de especialistas, aquel que viste tocado de caracoles - relacionado con la necesidad de control del agua, fertilidad y rituales de sacrificio de sangre que propicien buenas cosechas- y aquel que porta otro con aves -más relacionado con la recolección, la necesidad de sol que madure las cosechas, las aves, la música y la fiesta de recogida de frutos-.

Aunque hemos interpretado la "forma" de estas figuras para darles un sentido global en el conjunto de la cultura Jama Coaque, nos queda aún por averiguar cuál era la función de los recipientes, vasijas o esculturas en sí mismas. Es posible que como Zárate recogía para los templos de Bahía, estas figuras de chamanes se dispusieran a la entrada de los templos y formaran parte también del ajuar funerario de ciertos personajes. ¿Se trata entonces de imágenes de grandes sacerdotes o chamanes que habían conseguido conjurar grandes tormentas o salvar períodos de sequía a los que la comunidad quería recordar y aprovechar así su fuerza espiritual tras su fallecimiento? Que se trata de retratos individualizados no nos cabe duda, como veremos también a continuación.

\section{La mujer Jama-Coaque. Sacerdotisas y rituales de iniciación femeninos}

Además de este grupo de personajes masculinos, dentro de una mayor variedad de tipos humanos, destacan otros personajes, esta vez en relación con el sexo femenino, vinculados también con el universo ceremonial Jama Coaque.

Es frecuente reconocer en muchos museos del mundo, representaciones de cerámica de esta cultura que muestran figuras de mujeres adultas, erguidas, vestidas con faldas largas y complicados tocados, con tatuajes en hombros y brazos, pintura facial y una característica posición ritual de las manos (figura 4). Junto a este grupo destaca otro tipo de figuras femeninas, también frecuente, que muestra jóvenes sentadas en el suelo, con las piernas extendidas y juntas, un característico tocado y un objeto en forma de hatillo sobre sus piernas, que sostienen con la

8 En concreto, Deborah Pearsall (1994: 154-158) en su estudio arqueobotánico del Valle del Jama refiere la presencia de maíz, fríjoles, canavalia, mates, frutas de palma y guayaba, y semillas. Los fitolitos también ponen de manifiesto la existencia de tubérculos desde las etapas formativas tempranas, como achira, arrurruz, entre otros.

9 Jacinto de la Serna (1953 [1587]) menciona para México también a los "conjuradores de nublados" como especialistas rituales en el manejo mágico de las inclemencias del tiempo que se encargaban de ahuyentar temporales, tormentas y granizo, o atraer mágicamente el agua para los sembrados. 
mano (figura 5). Estos dos conjuntos de figuritas nos permiten definir dos actitudes de la mujer Jama Coaque, una como sacerdotisa y otra formando parte del rito de pubertad.

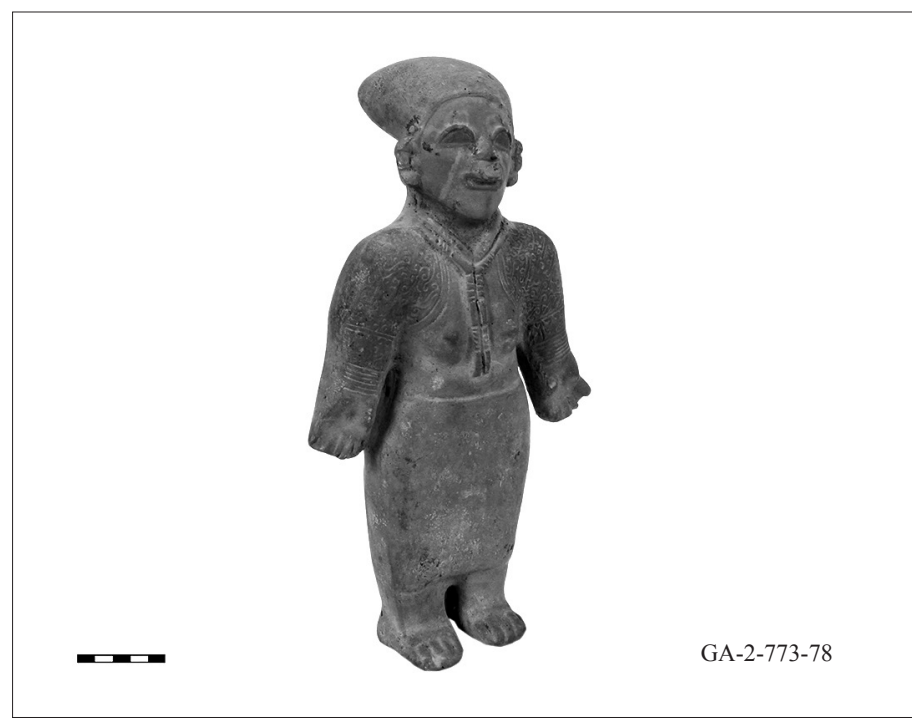

Figura 4. Mujer adulta vestida con falda larga

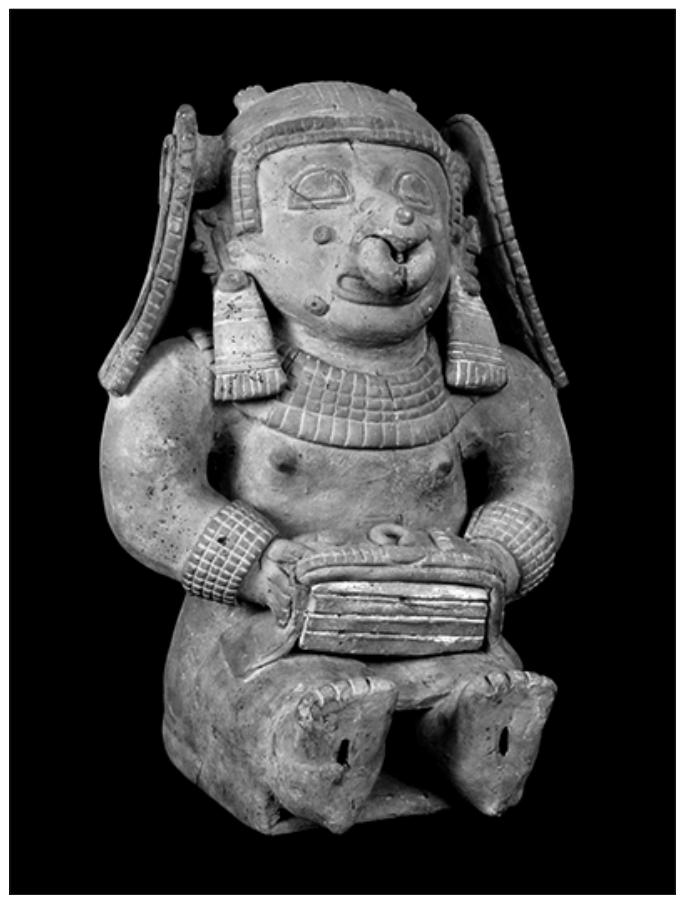

Figura 5. Joven Con un OBJeto en forma de hatillo 
En general, tanto las mujeres de un grupo como las jóvenes del otro, muestran rasgos corporales muy diferenciados, especificando proporciones físicas particulares, lo que parece sugerir que se trata de representaciones individualizadas de mujeres concretas que pertenecieron a un clan o familia -el cual se distingue por el tipo de tocado, pintura o decoración del faldellín-, con un rango social diferenciado -algunas se muestran sobre taburetes, o presentan más adornos y joyas que otras- y por mostrar unas características físicas que las individualizan -más esbeltas, obsesas, con deformaciones-. Se trata por tanto de retratos, más o menos esquematizados, de mujeres reales.

El primer grupo de estos dos que vamos a tratar, lo interpretamos como "sacerdotisas" con un característico tipo de tocado e indumentaria. A pesar de que las crónicas no refieren la existencia de este grupo social, sí que hemos observado su presencia en acontecimientos rituales realizados exclusivamente por sacerdotes, como el traslado del fardo funerario (Gutiérrez Usillos, 2011). Confirmamos por tanto que estas mujeres son sacerdotisas, equivalentes a los chamanes o sacerdotes masculinos, y comprobamos cómo frecuentemente se representan de forma similar, manifestando una posición ceremonial que es la que permite su reconocimiento como tales. En este tipo de iconografía, la mujer se muestra erguida, con los brazos caídos y mostrando las palmas de las manos abiertas y hacia el frente. La postura es hierática, la posición frontal y la mirada frontal. La longitud del faldellín de estas mujeres, en parte de ellas, más largo que en otros grupos femeninos de la misma cultura, podría tener relación con él estatus de la mujer representada.

\section{Ritual de iniciación de la pubertad femenina}

El otro conjunto destacado de representaciones femeninas está formado por jóvenes sentadas en el suelo -alguna sobre taburete- con las piernas extendidas, y un hatillo en el regazo. El aspecto físico correspondería al de jóvenes púberes en la menarquía a juzgar por la forma de los senos y abertura de botones mamarios, pero quizá el rasgo más sobresaliente es la presencia, invariablemente, de un tocado especial, que no se repite en otro tipo de representaciones. Se trata en realidad de una diadema con dos adornos laterales, que se sobrepone en la cabeza, dejando ver el cráneo liso, desprovisto de cabello. Estamos por tanto ante la presencia del ritual de iniciación femenina que incluye el corte de cabello.

Diversos grupos de toda América realizan la ceremonia del corte de cabello como parte del ritual de iniciación a la pubertad -los Cuna en Panamá o los Desana y los Tucuna, los Warraus, entre otros-. El rito incluye una fase de reclusión de la púber y tras la ceremonia de transformación pública, la joven está ya en disposición de contraer matrimonio.

Unos ritos de paso muy similares, pero desarrollados en los Andes Centrales, permiten visibilizar cuáles fueron los pasos básicos de este tipo de ritual de pubertad y extrapolar en cierto sentido a Jama Coaque:

"Usan trasquilar los hijos cuando llegan a tanta edad, de suerte que los cabellos con que nacen no llegan a ser en ellos adultos; y cuando los trasquilan en derredor de la cabeza dejan unas cernejas [mechones] de cabellos por las orillas del pelo, y algunas veces les trasquilan la mayor parte de la cabeza; a las mujeres les dejaban todos los cabellos del cogote entretejidos a manera de trenza... Para esta trasquila se solían juntar los caciques principales, si era hijo de principal; y, en acabando aquellas órdenes que se les daban, sentaban al muchacho en medio de todos, y allí llegaban todos a ofrecer de lo que cada uno podía: oro o plata en grano o piezas, de sus trajes ropa, o carneros o corderos o comida de máiz, papas, chuño u otras cosas. Esta fiesta duraba, con gran solemnidad y borrachera, hasta más de media noche, donde se perpetraban las maldades e insultos que ya he dicho... Después de tresquilado el muchacho, le ponen un birrete o bonete redondo, hecho por mano de su madre, con ciertos colgajos a manera de tiaras de mitra y con otras cosas colgando, borlas que es menester verlas para entenderlas, porque no hay lengua con que lo decir.... Esta ceremonia hacían a los varones; no he entendido que se hiciese en las mujeres. Llamábanla yavichico." (Álvarez, 1998 [1588]: 117-118). 
Además del tocado, en aquellos ejemplos en los que se conserva parte de la policromía, se observa en el rostro, manos y pies de estas figuras femeninas, la presencia de pigmentación de color amarillo anaranjado obtenida de distintos tipos de tierras y minerales. A diferencia del grupo femenino anterior no se aprecian tatuajes, así que este sólo se realizaba sobre un grupo concreto de mujeres, las sacerdotisas, mientras que el rito de paso sería realizado por todas las jóvenes.

En este ritual, el cabello podría ser cortado o arrancado. Pensamos que en Jama Coaque seguramente se realizaría de esta última forma mucho más dolorosa. Seguramente para poder soportar esta fase se produciría el consumo de alguna substancia alucinógena que viene sugerida por la disposición elevada de las pupilas de las jóvenes en estas figuritas, así como la boca entreabierta, mostrando una sonrisa forzada, un gesto habitual en casi todas las representaciones antropomorfas ritualizadas. El consumo de bebidas alucinógenas, no constatado en esta cultura, como las que se elaboran con Ipomoea violácea, está demostrado que provocan una sonrisa sin motivo y euforia.

Es curioso comprobar que, aunque este grupo de mujeres representa jóvenes adolescentes, muestran una mayor presencia de adornos faciales que otros grupos femeninos. Esto sugiere un interés por mostrar ostentación o evidenciar las posesiones de la joven, probablemente a modo de "dote" puesto que una vez concluido el ritual la muchacha se convierte en una joven casadera. El que algún ejemplar de este grupo reproduzca jóvenes con bebés en la espalda o embarazadas sólo significa que las relaciones sexuales estarían toleradas antes del matrimonio y que quizá una fase del rito de iniciación se realizaría conjuntamente para diferentes muchachas, de forma conjunta y no tanto en función de la biología de cada una.

Sin duda, lo que caracteriza este conjunto de figuras es la presencia invariable de un hatillo o paquete que sostiene sobre las piernas y que muestran diferentes objetos de adorno -narigueras, orejeras, collares...-, lo que ha motivado que se las viniera identificando como vendedoras de joyas. En un primer análisis de los hatillos con joyas se observan diferencias poco significativas o sustanciales. Todas las jóvenes muestran un atuendo muy similar, y el hatillo es bastante parecido, consistiendo en un textil doblado varias veces y rematado por un grupo de joyas. En ocasiones porta dos hatillos en lugar de uno, pero éstos son más cortos, por lo que es posible que el conjunto de joyas fuera el mismo, no existiendo grandes variaciones en el conjunto básico que recibe la joven. Si bien, hay que reconocer que estas representaciones femeninas muestran diferencias significativas, pues alguna muchacha se representa sentada en taburete -restringido al grupo de élite, sobre todo masculina-, lo que indicaría un rango o prestigio vinculado con su pertenencia a la familia.

En relación con el rito de paso femenino, a partir de estas representaciones Jama Coaque, se puede inferir la existencia de una doble ceremonia, como es común también entre otros grupos etnográficos. La primera, al aparecer la menarquía, consiste en el encierro ritual, que seguramente se ha representado en algunas vasijas cerámicas, y en la segunda, que parece despuntar como el aspecto más importante para esta cultura consiste en la incorporación de la "nueva" mujer a la sociedad, es decir la ceremonia de confirmación social del nuevo estatus, en la que probablemente se da un nuevo nombre y en la que se produce el rito del corte de cabello y consecuentemente la imposición del primer tocado, así como la entrega de la dote de la joven con ese rico ajuar para su futuro matrimonio.

\section{Conclusiones}

El análisis iconográfico permite recuperar información sobre las culturas arqueológicas incluso en aquellos aspectos cuya aproximación resulta de gran complejidad, al estar relacionados con el pensamiento religioso o con la cultura inmaterial, como es la realización de rituales y ceremonias. Este análisis, en muchas ocasiones, es la única forma que tenemos para acceder o entender este registro de patrimonio inmaterial de culturas del pasado. 
Debemos tratar de sistematizar el análisis iconográfico para poder realizar nuevas comparaciones, ya no solo dentro de la propia cultura analizada, sino también ampliando el ámbito de análisis en el espacio o en el tiempo. La propuesta de realizar una tabla de rasgos agrupada en torno a los cuatro conjuntos de elementos definidos, tal y como estamos ensayando en el proyecto Prometeo, parece una estrategia útil para el análisis y la relación y comparación entre los diferentes rasgos que muestran las representaciones antropomorfas Jama Coaque, que nos ha permitido el establecimiento de diferentes hipótesis e interpretaciones. Observamos cómo los grupos de rasgos se articulan de manera natural para mostrarnos los diferentes colectivos, especialistas o actividades que integran la sociedad Jama-Coaque.

Entre los personajes masculinos hemos destacado por el tipo de indumentaria y adornos, a los chamanes y dentro de estos a varios grupos de los que destacan los chamanes de tocados de caracoles y sus auxiliares acondroplásicos, y los chamanes de tocados de aves, lo que nos ha permitido distinguir los dos tiempos o espacios ceremoniales anuales, en torno a las fechas de siembra y recolección.

En el grupo de personajes femeninos también encontramos otros grupos vinculados con la religión, como son las sacerdotisas, o con el desarrollo de ceremonias de vital importancia para el sostenimiento del grupo, como son los ritos de paso de pubertad que supusieron un acontecimiento esencial para la integración del individuo en el grupo.

Queda todavía mucho por investigar en esta línea, y sobre todo avanzar en la correlación de las propuestas que surgen a partir de la interpretación iconográfica con nuevas investigaciones en el campo de la arqueología, que permitan entender mejor el uso y función de estos objetos cerámicos.

\section{Agradecimientos}

Este trabajo científico ha sido financiado por el Proyecto Prometeo de la Secretaría de Educación Superior de Ciencia, Tecnología e Innovación de la República del Ecuador.

Agradezco cordialmente el apoyo recibido también para la puesta en marcha de este proyecto tanto de Mariella García Caputi, como de Carolina Jervis, Sandra Solís y todo el personal del Museo de Antropología y Arte Contemporáneo (MAAC) de Guayaquil. 


\section{Bibliografía}

ÁLVAREZ, Bartolomé, 1998 [1588]. De las costumbres y conversión de los indios del Perú. Memorial a Felipe II (1598). Edición de $\mathrm{M}^{\mathrm{a}}$ del Carmen Martín Rubio, et al., Polifemo, Madrid.

GUTIÉRREZ USILLOS, Andrés, 2011. El Eje del Universo. Chamanes, sacerdotes y religiosidad en la cultura Jama Coaque del Ecuador Prehispánico, Ministerio de Cultura, Madrid.

HAMPE MARTÍNEZ, Teodoro, 1989. "El Reparto de metales, joyas e indios de Coaque: un episodio fundamental en la expedición de conquista de Perú", en: Quinto Centenario, 15: Universidad Complutense de Madrid, Madrid, pp.77-94.

PATIÑO, Víctor Manuel, 1958. "El cachipay o pijibay (Guilielma gasipaes Bailey), y su papel en la cultura y en la economía de los pueblos indígenas de América Tropical”, en: América Indígena, vol. XVIII-3 y 4, Instituto Indigenista Americano, México, pp. (3) 177-204; pp. (4) 299-332.

PEARSALL, Deborah M. 1994. "Análisis macrobotánico", en: Arqueología regional del norte de Manabí, Ecuador, vol. 1, University of Pittsburg, Pittsburgh, pp. 159-160.

DE LA SERNA, Jacinto, 1953 [1587]. Tratado de las supersticiones, idolatrías, hechicerías, ritos y otras costumbres gentilicas de las razas aborigenes de México, Fuente Cultural de la Librería Navarro, México.

TOBAR ABRIL, Oswaldo E, 1988. Prospección arqueológica en la cuenca del río Cangrejo en San Isidro, Manabi norte: el uso de criterios hidrográficos para el muestreo probabilístico, tesis de grado, ESPOL, Guayaquil.

UGALDE, María Fernanda, 2009. Iconografía de la Cultura Tolita. Lecturas del discurso ideológico en las representaciones figurativas del Desarrollo Regional, Riechert Verlag Wiesbaden, Berlín.

ZÁRATE, Agustín de, 1947 [1555]. "Historia del Descubrimiento y Conquista de la Provincia del Perú", en: Vedia, Enrique (director), Historiadores Primitivos de Indias, II, Atlas, BAE 26, Madrid, pp. 459-574.

ZEIDLER, J, 1994. "Investigaciones arqueológicas en el Valle Medio del Río Jama", en: Arqueología Regional del Norte de Manabi, Ecuador, vol. 1, Zeidler \& Pearsall (eds.), University of Pittsburgh, Pittsburgh, pp. $72-98$.

ZEIDLER, James y Marie Stuliff (Eds.), 1994. "Definición de los Complejos Cerámicos y Ocupación Cultural del Valle del Jama", en: Arqueología Regional del Norte de Manabi, Ecuador, Volumen 1, University of Pittsburgh, Pittsburgh pp. 112-130. 